\title{
SOSIALISASI LITERASI KOMUNIKASI KESEHATAN PENGOBATAN ALTERNATIF ISLAMI DI DESA HEGARMANAH KECAMATAN JATINANGOR
}

\author{
Susanne Dida, Evi Novianti, EInovani Lusiana, Saleha Rodiah, Trie Damayanti, \\ Rostika Yuliani, dan Mochammad Faidol Juddi \\ Fakultas Ilmu Komunikasi, Universitas Padjadjaran \\ E-mail: rostika.yuliani@gmail.com
}

\begin{abstract}
ABSTRAK. Perkembangan informasi saat ini semakin meningkat khususnya dalam hal informasi kesehatan. Keberadaan internet, sepaket dengan kebudayaan yang terbangun di dalam ruang publik baru membuat masyarakat sulit membedakan informasi faktual dan hoax. Adapun salah satu informasi kesehatan saat ini adalah informasi mengenai pengobatanpengobatan alternative berbasis islami. Salah satu jenis pengobatan tradisional berbasis islami yang diminati oleh masyarakat saat ini adalah pengobatan thibbun nabawi. Salah satu upaya yang dilakukan untuk meningkatkan kemampuan literasi komunikasi kesehatan adalah dengan cara memberikan informasi mengenai cara pengobatan alternative berbasis islami kepada masyarakat melalui kegiatan pengabdian kepada masyarakat. Kegiatan ini dilaksanakan dengan memberikan contoh-contoh kontemporer dan pemaparan terkait risiko-risiko dari ketersebaran hoax khususnya dalam hal informasi komunikasi kesehatan. Kegiatan ini dimaksudkan merupakan upaya membangun model edukasi dan literasi komunikasi kesehatan untuk meningkatkan kompetensi generasi muda dalam mengenali dan merespon hoax khususnya dalam hal komunikasi kesehatan. Tujuan dari kegiatan pengabdian kepada masyarakat ini adalah untuk terbentuknya wawasan masyarakat dengan pemilihan pengobatan alternative yang tepat dan terpercaya dan untuk mengetahui dan memahami pentingnya factor-faktor apa saja yang dapat menjadi acuan dalam memilih pengobatan alternatif. Hasil dan pembahasan yang diperoleh dari kegiatan ini adalah peserta terlihat sangat antusias dan mendapat pemahaman baru mengenai informasi seputar pengobatan alternative sehat serta masyarakat telah mengetahui jenis-jenis pengobatan dan tempat pengobatan alternative sehat yang dapat dipercaya dan tidak ada motif penipuan. Simpulan dari kegiatan ini adalah wawasan masyarakat akan adanya hoax dalam mencari informasi pengobatan alternative sudah terbentuk dengan baik, hal ini dilihat dari antusias para peserta mendapatkan pengetahuan dan informasi mengenai literasi informasi antara berita hoax dan berita secara resmi terutama dalam hal informasi di bidang kesehatan, mendapat pengetahuan mengenai macam-macam pengobatan alternative sehat.
\end{abstract}

Kata kunci: Literasi Komunikasi Kesehatan; pengobatan alternatif; pengabdian masyarakat

\begin{abstract}
The development of information is currently increasing, especially in terms of health information. The existence of the internet, a package with a culture that is built up in new public spaces makes it difficult for people to distinguish factual information and hoaxes. As for one of the current health information is information about alternative treatments based on Islam. One type of traditional Islamic-based treatment that is in demand by the public today is thibbun nabawi treatment. One of the efforts made to improve the literacy ability of health communication is by providing information on alternative ways of Islamic-based alternative treatment to the community through community service activities. This activity is carried out by providing contemporary examples and presentations related to the risks of hoax dispersal, especially in terms of health communication information. This activity is intended as an effort to build education models and health communication literacy to improve the competence of young people in recognizing and responding to hoaxes, especially in terms of health communication. The purpose of community service activities is to form community insights by choosing appropriate and trusted alternative treatments and to know and understand the importance of any factors that can be a reference in choosing alternative treatments. The results and discussion obtained from this activity were that participants seemed very enthusiastic and gained new understanding of information about healthy alternative medicine and the public knew the types of treatments and places of healthy alternative medicine that could be trusted and there were no fraud motives. The conclusion of this activity is the public insight into the existence of hoaxes in finding alternative medical information that has been well formed, this is seen from the enthusiasm of the participants to get knowledge and information about information literacy between hoax news and news officially, especially in terms of information in the health sector, get knowledge of various types of healthy alternative medicine.
\end{abstract}

Key words: Health Communication Literacy; alternative medicine; community service

\section{PENDAHULUAN}

Perkembangan informasi yang semakin cepat membuat masyarakat semakin penasaran akan informasi-informasi terutama dalam hal informasi kesehatan. Namun seringkali masyarakat merasa kebingungan akan informasi-informasi yang beredar apakah informasi itu bersifat resmi ataupun bersifat hoax. Hoax merupakan informasi yang direkayasa untuk menutupi informasi sebenarnya. Dengan kata lain hoax juga bisa diartikan sebagai upaya memutarbalikan fakta menggunakan informasi yang seolah-olah meyakinkan tetapi tidak dapat diverifikasi kebenarannya. Hoax juga bisa diartikan sebagai tindakan mengaburkan informasi yang sebenarnya, dengan cara membanjiri suatu media 
dengan pesan yang salah agar bisa menutupi pesan yang benar. Tujuan dari hoax yang disengaja adalah membuat masyarakat merasa tidak aman, tidak nyaman, dan kebingungan. Dalam kebingungan, masyarakat akan mengambil keptusan yang lemah, tidak meyakinkan, dan bahkan salah.

Literasi informasi kesehatan atau dapat disebut dengan literasi kesehatan ini menggambarkan berbagai tingkatan yang ada didalamnya serta memiliki peran penting dalam pemberdayaan masyarakat. Pertama, tingkatan dasar literasi kesehatan ini berupa kemampuan dasar untuk membaca dan memahami bahan penting untuk kesehatan yang akan diperlukannya, seperti membaca resep, label obat maupun petunjuk perawatan kesehatan. Kedua, tingkatan menengah dimana individu sudah memiliki pengetahuan dari tingkatan pertama yang akan dikaitkan dengan informasi yang ada dilingkungan. Kemudian ketiga, tingkatan tinggi yang merupakan perpaduan dari kedua tingkatan dasar dan menengah yang dapat mencerminkan kemampuan yang dimiliki individu dalam menganalisis berbagai informasi yang ada dan untuk selanjutnya dapat mempublikasikan informasi yang telah diperolehnya untuk orang lain supaya dapat menambah informasi terutama dalam bidang kesehatan.

Salah satu informasi kesehatan yang paling sering dikeluhkan oleh masyarakat adalah informasi mengenai pengobatan alternatif baik itu pengobatan alternatif secara tradisional ataupun pengobatan alternatif berbasis islami atau yang dikenal dengan sebutan thibbun nabawi. Istilah Thibbun Nabawi dimunculkan oleh para dokter muslim sekitar abad ke$13 \mathrm{M}$ untuk menunjukkan ilmu-ilmu kedokteran yang berada dalam bingkai keimanan pada Allah, sehingga terjaga dari kesyirikan, takhayul dan khurofat.

Pengobatan alternatif ini khususnya pengobatan berbasis islami yang dikenal dengan sebutan thibbun nabawi ini menjadi salah satu opsi masyarakat dalam mengatasi persoalan di bidang kesehatan. Adapun banyak alasan masyarakat ingin mencoba pengobatan alternatif khususnya pengobatan thibbun nabawi diantaranya adalah faktor ekonomi, karena pengobatan alternatif berbasis islami ini dari segi biaya jauh lebih terjangkau dibandingkan dengan pengobatan secara medis. Dari segi faktor sosial budaya yang dimana stigma masyarakat akan pengobatan alternatif khususnya pengobatan alternatif berbasis islami ini dapat menyembuhkan berbagai macam penyakit dan pengobatan alternatif berbasis islami yang dikenal dengan thibbun nabawi ini merupakan salah satu pengobatan yang prosesnya mengacu atau merujuk kepada tindakan dan perkataan (hadist) Nabi Muhammad mengenai penyakit, pengobatan dan kebersihan maupun genre tulisan oleh para sarjana non-medis untuk mengumpulkan dan menjelaskan tradisi-tradisi tersebut. (Wikipedia,2018)

Hasil studi pendahuluan, bahwa Warga Desa Hegarmanah Kecamatan Jatinangor pada umumnya ada yang sudah pernah dan mengetahui informasi tentang pengobatan alternatif khususnya pengobatan thibbun nabawi dan ada juga yang belum pernah melakukan pengobatan alternatif khususnya thibbun nabawi, namun yang menjadi kendala para warga adalah kurangnya pemahaman dan sosialisasi untuk membedakan informasi mengenai pengobatan alternatif itu apakah bersifat hoax atau bersifat resmi Adapun dasar hukum mengenai pengobatan alternatif ini diatur di dalam Peraturan Menteri Kesehatan Nomor 37 Tahun 2017 tentang Pelayanan Kesehatan Tradisional Integrasi, Peraturan Menteri Kesehatan Republik Indonesia Nomor 61 Tahun 2016 tentang Pelayanan Kesehatan Tradisional Empiris dan Peraturan Menteri Kesehatan Republik Indonesia Nomor 15 Tahun 2018 Tentang Penyelenggaraan Pelayanan Kesehatan Tradisional Komplementer.

Meskipun pengobatan medis ini sudah jauh lebih canggih dan menggunakan teknologi secara modern, namun pengobatan alternatif ini dinilai masih menjadi favorit masyarakat khususnya warga Desa Hegarmanah Kecamatan Jatinangor dengan alasan pengobatan alternatif berbasis islami ini lebih menekankan pada pengobatan yang diajarkan sesuai sunnah rasul dan kebanyakan pengobatan alternatif berbasis islami ini sudah memiliki sertifikasi berupa surat ijin praktek berobat sehingga masyarakat tidak meragukan akan izin prakteknya. Maka dari itu diperlukan suatu kegiatan untuk memberikan pemahaman kepada masyarakat khususnya warga Desa Hegarmanah Kecamatan Jatinangor tentang literasi komunikasi kesehatan khususnya informasi mengenai pengobatan alternatif berbasis islami yang dikenal dengan Thibbun nabawi dan upaya mencegah anti hoax terhadap informasi kesehatan khususnya pengobatan alternatif berbasis islami yaitu thibbun nabawi.

\section{METODE}

Metode kegiatan PKM ini terdiri dari beberapa tahapan diantaranya tahap persiapan, tahap pelaksanaan sosialisasi dan tahap evaluasi kegiatan.

1. Persiapan

Tahap ini merupakan tahap awal sebelum pelaksanaan kegiatan sosialisasi. Adapun di dalam tahapan ini ada beberapa kegiatan yang dilakukan oleh tim KKNM PPMD Unpad untuk merencanakan pelaksanaan secara konseptual, operasional, lalu menentukan jumlah peserta sosialisasi, pembuatan instrumen pkm seperti absensi, pedoman wawancara \& kuisioner, buku 
saku dan terakhir persiapan konsumsi, publikasi dan dokumentasi serta persiapan lokasi.

2. Pelaksanaan sosialisasi

Tahap ini merupakan tahap sosialisasi sekaligus tahap proses pendampingan yang dilakukan kepada para peserta dalam hal ini para warga Desa Hegarmanah Kecamatan Jatinangor. Pelaksasnaan sosialisasi ini meliputi beberapa hal diantaranya :

A. Penyajian materi

Materi yang disajikan terkait dengan terkait dengan informasi serta pemahaman akan hoax di media sosial khususnya informasi kesehatan, macam-macam pengobatan alternatif berbasis islami dan diskusi mengenai pengalaman dari para warga serta mahasiswa tentang pengoatan alternative berbasis islami khususnyathibbunnabawi.Adapun penyajian ini diploting dalam kurun waktu satu hari tatap muka dan materi yang disampaikan adalah hoax di media sosial khususnya tentang informasi kesehatan dan macammacam pengobatan alternatif berbasis islami. Setelah proses pemberian materi selesai akan dilakukan proses pendampingan para peserta dengan melibatkan para mahasiswa KKNM dan tim PPMD yang lain.

B. Penugasan

Pada akhir materi peserta diberikan kuisioner dan beberapa peserta yang sudah pernah berobat dengan pengobatan alternative berbasis islami diminta untuk wawancara secara mendalam mengenai pengobatan alternative berbasis islami. Dalam praktik ini, para peserta sosialisasi ditugaskan untuk menjawab pertanyaan mengenai kepercayaan terhadap pengobatan alternative, makna dan motif berobat secara islami dan pola komunikasi dalam proses pengobatan alternative secara islami. Tim PPMD Unpad bersama para mahasiswa KKNM kemudian mendampingi semua proses kegiatan dan memberikan instruksi atau arahan pada halhal yang masih kurang dipahami oleh para peserta. Adapun Kegiatan Proses sosialisasi Pengobatan Alternatif anti Hoax dapat dilihat pada gambar berikut

C. Penutupan

Setelah semua kegiatan yang telah direncanakan terlaksana, ketua tim KKNM PPMD Unoad menutup program dan memberikan pesan kepada segenap peserta untuk menerapkan informasi apa yang telah di dapatkan dari kegiatan sosialisasi tersebut. Diharapkan PKM yang akan datang, sosialisasi seperti ini dapat dilanjukan kembali dengan materi yang sama dan tema yang sama dan mampu menjangkau masyarakat lebih banyak lagi.

\section{3) Evaluasi Kegiatan Sosialisasi}

Evaluasi dapat dilihat dengan beberapa cara dilihat dari antusiasme para warga untuk datang menghadiri sosialisasi, keberhasilan materi yang disajikan serta kinerja dari para peserta dalam menjawab instrumen yang diberikan oleh panitia dalam hal ini tim KKNM PPMD Unpad baik itu kuisioner maupun wawancara. Adapun Rincian Kegiatan Sosialisasi dapat dilihat pada tabel berikut

Tabel 1. Kegiatan Sosialiasi Pengobatan Alternatif Berbasis Islami Anti Hoax

\begin{tabular}{|c|c|c|c|c|}
\hline \multirow{2}{*}{ No } & \multirow{2}{*}{ Rencana Kegiatan } & \multicolumn{3}{|c|}{ Keterlibatan dalam Kegiatan } \\
\hline & & Dosen & Mahasiswa & Peserta \\
\hline 1 & Tahap Persiapan & $\begin{array}{l}\text { 1. Melakukan persiapan } \\
\text { materi sosialisasi } \\
\text { 2. Menyiapkan bahan- } \\
\text { bahan untuk penelusuran } \\
\text { informasi }\end{array}$ & $\begin{array}{l}\text { 1. Melakukan koordinasi } \\
\text { dengan pihak desa dan } \\
\text { kecamatan } \\
\text { 2. Menyiapkan Surat } \\
\text { Undangan untuk } \\
\text { perangkat desa dan warga }\end{array}$ & $\begin{array}{l}\text { 1. Melakukan sharing } \\
\text { pengalaman tentang } \\
\text { pengobatan alternative } \\
\text { berbasis islami }\end{array}$ \\
\hline 2. & Tahap Pelaksanaan & $\begin{array}{l}\text { 1. Memberikan Materi } \\
\text { Ceramah } \\
\text { 2. Memberikan Sosialisasi } \\
\text { 3. Memberikan Sesi Diskusi } \\
\text { kepada para warga untuk } \\
\text { menceritakan tentang } \\
\text { pengalaman pengobatan } \\
\text { alternatif berbasis islami }\end{array}$ & $\begin{array}{l}\text { 1. Menyiapkan acara } \\
\text { sosialisasi } \\
\text { 2. Membantu kegiatan } \\
\text { sosialisasi } \\
\text { 3. Berperan aktif untuk } \\
\text { menceritakan pengalaman } \\
\text { pengobatan alternatif } \\
\text { berbasis islami }\end{array}$ & $\begin{array}{l}\text { 1. Membantu pelaksanaan } \\
\text { kegiatan sosialisasi } \\
\text { dengan cara menjawab } \\
\text { instrumen pkm yang } \\
\text { diberikan oleh tim }\end{array}$ \\
\hline 3 & $\begin{array}{l}\text { Tahap penyusunan dan penggandaan } \\
\text { laporan }\end{array}$ & $\begin{array}{l}\text { Melakukan penyusunan } \\
\text { laporan dan penggandaan }\end{array}$ & $\begin{array}{l}\text { Membantu menyiapkan } \\
\text { data-data penunjang dan } \\
\text { melengkapi berkas-berkas } \\
\text { administratif seperti } \\
\text { absensi dll. }\end{array}$ & $\begin{array}{l}\text { Melakukan konsultasi } \\
\text { kepada peserta untuk } \\
\text { mengetahui respon terhadap } \\
\text { kegiatan sosialisasi } \\
\text { pengobatan alternatif }\end{array}$ \\
\hline
\end{tabular}




\section{HASIL DAN PEMBAHASAN}

Literasi kesehatan menjadi bagian yang sangat penting dalam konteks pembangunan kesehatan. Upaya menyadarkan masyarakat harus dengan pengetahuan sampai sejauh mana kemampuan masyarakat dalam mengakses informasi kesehatan, sejauh mana kemampuan masyarakat dalam memahami informasi kesehatan yang diperolehnya melalui petugas kesehatan maupun melalui media yang tersedia.

Institusi kesehatan dan petugas kesehatan juga harus memiliki pengetahuan tentang budaya yang melingkupi masyarakat dimana mereka berada. Budaya ditengarai mempengaruhi konsep sehat yang berimplikasi pada praktik praktik pencegahan atau pengobatan yang tidak sesuai dengan pandangan petugas kesehatan. Semua hal tersebut di atas merupakan masalah yang biasanya menjadi wilayah kajian dalam literasi kesehatan.

Dasar hukum tentang pengobatan alternative ini diatur di dalam Peraturan Menteri Kesehatan Nomor 37 Tahun 2017 tentang pelayanan kesehatan tradisional terintegrasi yang dimana dijelaskan dalam pasal 5 dan pasal 6 kriteria pelayanan kesehatan tradisional terintegrasi ini diantaranya terbukti secara ilmiah; b. dilaksanakan sesuai dengan kebutuhan terbaik pasien; dan c. memiliki potensi promotif, preventif, kuratif, rehabilitatif, dan meningkatkan kualitas hidup pasien secara fisik, mental, dan sosial Pasal 6 Pelayanan Kesehatan Tradisional Integrasi harus dilakukan dengan tata laksana: a. pendekatan holistik dengan menelaah dimensi fisik, mental, spiritual, sosial, dan budaya dari pasien. b. mengutamakan hubungan dan komunikasi efektif antara tenaga kesehatan dan pasien; c. diberikan secara rasional; d. diselenggarakan atas persetujuan pasien (informed consent); e. mengutamakan pendekatan alamiah; f. meningkatkan kemampuan penyembuhan sendiri; dan g. pemberian terapi bersifat individual. Pengobatan Alternative ini juga memiliki surat tempat praktek juga yang diatur juga di dalam Peraturan Menteri Kesehatan Republik Indonesia Nomor 61 Tahun 2016 tentang Pelayanan Kesehatan Tradisional Empiris pasal 4 ayat 1 tentang Surat Terdaftar Penyehat Tradisional (STPT) bahwa Penyehat Tradisional yang akan melakukan Pelayanan Kesehatan Tradisional Empiris wajib memiliki STPT; dan Peraturan Menteri Kesehatan Republik Indonesia Nomor 15 Tahun 2018 Tentang Penyelenggaraan Pelayanan Kesehatan Tradisional Komplementer dimana cara Pengobatan/Perawatan, Pelayanan Kesehatan Tradisional Komplementer dilakukan dengan menggunakan: a. keterampilan; b. ramuan; atau c. kombinasi dengan memadukan antara keterampilan dan ramuan.
Pengobatan Alternatif Berbasis Islami juga merupakan bagian dari pelayanan kesehatan tradisional komplementer yang dimana memadukan antara keterampilan yaitu keterampilan terapis dalam melakukan proses pengobatan dengan menggunakan doa-doa dan sunnah rasul dan ramuannya yaitu dengan menggunakan bahan-bahan alami. Adapun macam-macam pengobatan berbasis islami diantaranya adalah terapi acupressure, terapi chiropractic, pijat refleksi, totok, terapi sengat lebah, bekam, ruqyah, terapi al-fashdu, terapi su jok dan masih banyak terapi-terapi yang lainnya.

Implementasi program pengabdian kepada masyarakat dimulai dengan melakukan koordinasi dengan pihak kepala desa, kecamatan dan warga desa hegarmanah kecamatan jatinangor untuk menyusun jadwal pelaksanaan kegiatan, menyiapkan tempat kegiatan, menyiapkan sarana dan prasarana dll. Koordinasi dengan pihak kepala desa, kecamatan dan warga desa dilakukan dengan mengirimkan surat undangan. Adapun secara umum proses kegiatan sosialisasi pengobatan alternative telah dijelaskan di dalam tabel 1.

Materi sosialisasi mengenai hoax khususnya dalam hal informasi kesehatan, pengobatan alternatif berbasis islami, macam-macam pengobatan alternatif berbasis islami yang disajikan dalam bentuk buku saku dan powerpoint serta ceramah yang bertujuan agar mudah dicerna dan dipahami oleh para peserta. Oleh karena itu, tim mencoba menyusun materi yang sederhana, singkat dan mampu dipahami secara langsung oleh para peserta.

Sebagai puncak kegiatan sosialisasi adalah sharing pengalaman dan diskusi antara perwakilan tim KKNM PPMD Unpad yang diwakili oleh beberapa perwakilan mahasiswa dengan masyarakat. Keberhasilan suatu kegiatan sosialisasi juga ditentukan bukan saja oleh materi dan narasumber tetapi juga oleh metode dan media pembelajarannya. Sosialisasi adalah pendidikan bagi orang dewasa sehingga memerlukan pendekatan yang pas, yaitu dengan multi metode dan multi informasi. Dalam hal ini selain metode konvensional yang biasa digunakan yaitu ceramah dan tanya jawab, tetapi dilakukan secara mendalam dengan cara diskusi mendalam melalui kegiatan wawancara, sehingga partisipasi peserta akan meningkat dan tidak menjemukan,selain itu juga digunakan informasi berupa ilustrasi fotofoto kegiatan dan proses pengobatan alternatif berbasis islami yang dilakukan oleh para mahasiswa. Dengan informasi yang demikian maka kegiatan sosialisasi menjadi dinamis dan sangat menarik. Hal ini juga menjadi salah satu metode dan informasi yang menarik dan berhasil memberikan pemahaman dan kemampuan yang sangat baik bagi peserta. Penerapan multi metode dan multi informasi 
dalam kegiatan sosialisasi ini menjadikan PKM berlangsung secara dinamis dan membuat suasana kegiatan sosialisasi menjadi semakin menarik dan semakin lebih mendalam, peran serta dan partisipasi peserta meningkat, terbukti dengan banyaknya peserta yang mengemukakan pendapat menceritakan pengalamannya baik yang sudah pernah berobat dengan menggunakan pengobatan berbasis islami ataupun yang belum pernah berobat. Hal ini muaranya adalah terbentuknya pemahaman peserta terhadap materi sosialisasi secara kompehensif.

Kesan dan tanggapan peserta dalam sosialisasi ini sangat positif, hal ini ditunjukkan dengan absensi kehadiran, bahasan dan tanggapan waktu penyajian materi dengan berbagai pertanyaan dan diskusi tentang materi secara interaktif, serta harapan agar sosialisasi ini masih ditindaklanjuti dengan kajian yang lebih luas dan mendalam.

\section{SIMPULAN}

Setelah dilakukan kegiatan sosialisasi kepada masyarakat khususnya warga Desa Hegarmanah Kecamatan Jatinangor diperoleh beberapa kesimpulan diantaranya adalah para peserta mendapatkan pengetahuan dan informasi mengenai literasi informasi antara berita hoax dan berita secara resmi terutama dalam hal informasi di bidang kesehatan, mendapat pengetahuan mengenai macam-macam pengobatan alternatif berbasis islami dan cara berobatnya. Setelah mendapat pengetahuan dan informasi tersebut diharapkan masyarakat khususnya warga Desa Hegarmanah Kecamatan Jatinangor akan memiliki banyak informasi dan wawasan mengenai hoax di bidang kesehatan dan pengobatan alternatif berbasis islami.

\section{DAFTAR PUSTAKA}

Gumgum Gumilar, J. A. dan N. M. (2017). Literasi Media: Cerdas Menggunakan Media Sosial Dalam Menanggulangi Berita Palsu (Hoax) Oleh Siswa Sma. Jurnal Pengabdian Kepada Masyarakat, 1(1), 35-40.

Pawit M. Yusup, E. S. (2017). Praktik Literasi Informasi Dalam Proses Pembelajaran Sepanjang Hayat. Jurnal Kajian Informasi \& Perpustakaan, 5(1), 79-94.

Peraturan Kementerian Kesehatan Republik Indonesia Nomor 61 Tahun 2016 Pelayanan Kesehatan Tradisional Empiris. Lembaran Negara Republik Indonesia Tahun 2016 Nomor 1994. Jakarta.

Peraturan Kementerian Kesehatan Republik Indonesia Nomor 37 Tahun 2017 Pelayanan Kesehatan Tradisional Integrasi. Lembaran Negara Republik Indonesia Tahun 2017 Nomor 1074. Jakarta.

Peraturan Kementerian Kesehatan Republik Indonesia Nomor 15 Tahun 2018 Pelayanan Kesehatan Tradisional Komplementer . Lembaran Negara Republik Indonesia Tahun 2018 Nomor 940. Jakarta.

Purwanti Hadisiwi, J. R. S. (2016). Literasi Kesehatan Masyarakat Dalam Menopang Pembangunan Kesehatan Di Indonesia. Prosiding Seminar Nasional Komunikasi, 344-351.

Wikipedia. (2018). Thibbun nabawi. Retrieved from https://id.wikipedia.org/wiki/Thibbun Nabawi 